\title{
An innovative approach to the study of word learning biases
}

\section{Lauren Krogh*}

Psychology, University of California Los Angeles, Los Angeles, CA, USA

*Correspondence: laurenkrogh@gmail.com

\section{A commentary on}

The shape of the vocabulary predicts the shape of the bias

by Perry, L. K., and Samuelson, L. K. (2011). Front. Psychol. 2:345. doi: 10.3389/ fpsyg.2011.00345

A key question of development is how children detect structure in the environment and use that structure to guide future learning. This is a question of particular interest to researchers investigating language and category development. There is now an extensive body of research demonstrating that the difficulty of first language acquisition and generalization is alleviated by a variety of word learning biases and constraints children may employ (e.g., Landau et al., 1988; Markman, 1989, 1992; Merriman et al., 1989; Waxman and Kosowski, 1990). Perry and Samuelson (2011) focus on one of the most recently studied and well-documented biases, the "shape bias." However, in contrast to the ways in which cognitive developmentalists have traditionally investigated this bias, Perry and Samuelson adopt a new approach, focusing on how individual differences in children's vocabulary structure guide online attention during novel noun generalization.

The shape bias refers to children's tendency to extend object labels on the basis of similarity in shape rather than size, color, or material. Previous research has focused on how the size and structure of children's noun vocabulary, particularly the number of words children produce labeling categories organized by similarity in shape or material, relate to shape bias development (e.g., Samuelson and Smith, 1999). With very few exceptions (e.g., Gershkoff-Stowe and Smith, 2004), this research has also focused entirely on children's performance as a group. In marked contrast, Perry and Samuelson (2011) introduce a novel approach to studying word learning biases by focusing on individual differences in children's vocabulary development and employing an innovative measure of children's vocabulary structure: "against the system" nouns.

According to Perry and Samuelson (2011), "against the system" nouns derive their name from their inability to be classified on only one side of the ontological divide between categories defined by shape (solid + shape + count) and categories defined by material (nonsolid + material + mass). Perry and Samuelson demonstrate that the size of individual children's "against the system" vocabulary is a key predictor of individual children's shape bias, more so than traditional measures of children's vocabulary for objects defined by shape or material. In doing so, they provide strong support for the role of prior learning in shaping future learning, and illustrate how online attention may be an important factor mediating this relation.

Where do individual differences in young children's vocabularies originate? Factors such as gender and exposure to speech have been found to contribute to individual differences in children's rate of vocabulary growth (e.g., Huttenlocher et al., 1991). However, it is not yet known whether these or other factors may also contribute to differences in early vocabulary structure. In all likelihood, there are a host of factors leading to the individual differences observed in the early stages of children's word learning, including characteristics of the child (e.g., gender, activity level, learning capacity) as well as characteristics of the caregiver (e.g., level of interaction with the child) and of the physical environment (e.g., exposure to particular objects and people). Critically, however, Perry and Samuelson's (2011) data suggest that the key to understanding early individual differences in vocabulary structure may lie not in examining such factors in isolation, but in considering the role each such factor may play in shaping children's early attentional biases. For just as individual differences in vocabulary structure influence children's noun generalization and attentional biases, it is probable that initial and/or prelinguistic attentional biases play a key role in the acquisition of children's varied early vocabularies. Future research should address such initial attentional biases and how they may influence early word learning as well as later attentional biases.

Perry and Samuelson (2011) introduce an exciting new way of conceptualizing and investigating children's language and category development that has far-reaching applications for developmental science. By this account, the key questions involve how prior experiences with language, objects, and people work together to guide attention and how individual differences in attention produce differences in in-the-moment learning. Approaching development from this perspective will push the field forward in answering questions about how the structure of the child's environment relates not only to the development of word learning biases, but also to thinking and learning more broadly.

\section{REFERENCES}

Gershkoff-Stowe, L., and Smith, L. B. (2004). Shape and the first hundred nouns. Child Dev. 74, 1098-1114.

Huttenlocher, J., Haight, W., Bryk, A., Seltzer, M., and Lyons, T. (1991). Early vocabulary growth: relation to language input and gender. Dev. Psychol. 27, 236-248.

Landau, B., Smith, L. B., and Jones, S. S. (1988). The importance of shape in early lexical learning. $\operatorname{Cog} n$. Dev. 3, 299-321.

Markman, E. M. (1989). Categorization and Naming in Children. Cambridge, MA: MIT Press.

Markman, E. M. (1992). “Constraints on word learning: speculations about their nature, origins, and domain specificity," in Modularity and Constraints in Language and Cognition. The Minnesota Symposia on Child Psychology, eds M. R. Gunnar and M. Maratsos (Hillsdale, NJ: Lawrence Erlbaum Associates), 59-101.

Merriman, W. E., Bowman, L. L., and MacWhinney, B. (1989). The mutual exclusivity bias in children's word learning. Monogr. Soc. Res. Child Dev. 54, 1-129. 
Perry, L. K., and Samuelson, L. K. (2011). The shape of the vocabulary predicts the shape of the bias. Front. Psychol. 2:345. doi: 10.3389/fpsyg.2011.00345

Samuelson, L. K., and Smith, L. B. (1999). Early noun vocabularies: do ontology, category organization and syntax correspond? Cognition 73, 1-33.

Waxman, S. R., and Kosowski, T. D. (1990). Nouns mark category relations: toddlers' and preschoolers' word-learning biases. Child Dev. 61, 1461-1473.

Received: 16 December 2011; accepted: 08 February 2012; published online: 24 February 2012.

Citation: Krogh L (2012) An innovative approach to the study of word learning biases. Front. Psychology 3:48. doi: 10.3389/fpsyg.2012.00048
This article was submitted to Frontiers in Developmental Psychology, a specialty of Frontiers in Psychology.

Copyright $\odot 2012$ Krogh. This is an open-access article distributed under the terms of the Creative Commons Attribution Non Commercial License, which permits non-commercial use, distribution, and reproduction in other forums, provided the original authors and source are credited. 